\title{
A GERAÇÃO SILVER NO CURSO DE DIREITO: DISCENTE, DISCIPLINA, EXTENSÃO E PESQUISA
}

SILVER GENERATION IN THE COURSE OF LAW: DISCIPLINE, DISCIPLINE, EXTENSION AND

RESEARCH

Sheila Marta Carregosa ROCHA ${ }^{1}$

ISSUE DOI: $10.21207 / 1983.4225 .605$

\section{RESUMO}

A pessoa idosa está se reinventando para garantir um envelhecimento ativo. No ensino brasileiro, está ocupando seu espaço na educação de jovens e adultos ou nas Universidades formais ou abertas à Terceira Idade. Direitos dos Idosos lançada como disciplina optativa nos cursos de Direito. Ademais, como

\footnotetext{
${ }^{1}$ Pós-Doutorado em Família na Sociedade Contemporânea (UCSAL) Pós-Doutorado em Sociologia do Envelhecimento pela Universidade do Porto (Portugal). Doutora em Família na Sociedade Contemporânea (UCSal,2015). Bolsista da CAPES para estágio Doutoral na Universidade do Porto em Portugal (2014). Mestre em Família na Sociedade Contemporânea (UCSal,2012). Especialista em Direito Civil pela Fundação Faculdade de Direito (UFBA, 2007). Especialista em Metodologia do Ensino Superior com Ênfase em Novas Tecnologias (FBB,2002). Especialista em Psicopedagogia (UFRJ,2000). Bacharela em Direito (FIB, 2005). Licenciada em Letras Vernáculas (Universidade Católica do Salvador, 1994). Servidora Pública. Pesquisadora do Núcleo de Estudos sobre Governação e Instituições e do Núcleo de Estudos em Direitos Humanos da Pós-Graduação stricto sensu da Universidade Católica do Salvador. Pesquisadora do Grupo de Pesquisa em "Educação Direitos humanos e Fronteira" da Universidade Federal do PAMPA. Docente da Universidade do Estado da Bahia (UNEB) do Departamento de Ciências Humanas do Campus XX - Brumado nas disciplinas de Direito Processual Civil e Direito de Família. Docente da Universidade do Estado da Bahia, Campus XV - Valença, nas disciplinas de Direito Civil e Processo Civil. Professora da Pós-Graduação de Direito da FAMEC, FTC. Membro associada ao Conselho Nacional de Pesquisa e Pós-Graduação em Direito (CONPEDI). Membro do Conselho editorial da Revista da UNIVAP 2018. Lider do Grupo Direitos Humanos, Envelhecimento e Violências, certificado pela UNEB e inscrito no Diretório dos grupos de Pesquisa do CNPq, DHEV/UNEB/Cnpq dgp.cnpq.br/dgp/espelhogrupo/1551266856460047.
} 
projeto de extensão, as UATI, cursos e eventos para a pessoa idosa. Há grupos de pesquisa voltados para a investigação desse sujeito de direitos. De natureza multidisciplinar, investigada pela Gerontologia e demais ramos das Ciências da Saúde, Sociologia e demais ramos das Ciências Sociais e a Pedagogia e outros ramos das Ciências Humanas.

Palavras-chave: Pessoa Idosa. Universidade. Ensino-Pesquisa e Extensão.

\begin{abstract}
The elderly person is reinventing himself to ensure active aging. In Brazilian education, it is occupying its space in the education of youngsters and adults or in universities that are formal or open to the Third Age. Rights of the Elderly, launched as an elective course in Law courses. In addition, as an extension project, the UATI, courses and events for the elderly. There are research groups focused on the research of this subject of rights. Of a multidisciplinary nature, investigated by Gerontology and other branches of Health Sciences, Sociology and other branches of Social Sciences and Pedagogy and other branches of Human Sciences.
\end{abstract}

Keywords: Elderly. University. Teaching-Research and Extension.

\title{
INTRODUÇÃO
}

A metodologia de abordagem quantitativa foi utilizada pela mapear a população idosa no Brasil que está em constante crescimento, em 2005 era de 9,9\% da população brasileira, dez anos depois, em 2015, já contava com 14,3\% (PNAD, 2015, p.37), e pensando na distribuição por regiões, Sudeste e Sul registraram os maiores percentuais de idosos (15,7\% e $16,0 \%$, respectivamente), enquanto a Região Norte, o menor (10,1\%), a região nordeste 13,4\%, e a região centro-oeste 12,1\% (PNAD, 2015, p.38). Isto significa que se pode analisar, considerando algumas variáveis, através da metodologia de abordagem qualitativa, que as pessoas têm melhores condições de saúde para o envelhecimento nessas regiões. Estima-se que em 2060 a população brasileira será de 58 milhões de idosos. Onde estão e estarão essas pessoas? Nas filas dos postos de saúde? Nas Instituições de Longa Permanência? Nas famílias como um ônus de cuidar e manter? A proposta deste artigo é a manutenção da mente ativa e saudável evita muitos males, estigmas e mitos.

A educação é um caminho também para pessoa idosa. O Instituto Brasileiro de Geografia e Estatística(2015) considera alguns indicadores para medir a educação no Brasil: alfabetização, taxa de analfabetismo, estudante, taxa de escolarização, frequência à escola, rede de ensino, área da rede pública, duração do ensino fundamental, anos de estudo, acesso à internet no domicílio, utilização da internet em algum local e telefone móvel celular para uso pessoal. 
A partir desses indicadores, esta pesquisa mostra os resultados da investigação sobre o perfil da pessoa idosa na educação formal brasileira, além de mapear universidades formais em que os idosos estão entre os discentes com outras faixas etárias, e universidades abertas à terceira idade que oferecem cursos livres voltados para o bem-estar e o envelhecimento ativo, não mais voltado para qualificação para o mercado de trabalho.

Logo, utilizou-se o método indutivo, com as especificidades da pesquisa em dados secundários fornecidos pelo IBGE, além dos sítios de pesquisa das Universidades na internet, que permitiram relacionar com o referencial teórico interdisciplinar do Direito com a Sociologia, a Gerontologia e a Pedagogia, para discutir sobre esse novo-velho interesse das pessoas idosas, quer porque nunca tiveram oportunidade de ingressar numa universidade, ou porque seja um espaço de socialização, ou precisam se manter no mercado de trabalho, e essa é outra oportunidade de buscar diversificar a vida laboral, para além da aposentadoria.

Constituindo as técnicas de pesquisa escolhidas para refletir sobre a pessoa idosa que está no centro das atenções da extensão, da pesquisa e busca conquistar o ensino através dos cursos formais, resignificando a tese de que a Universidade é o espaço para a qualificação para o trabalho do jovem, abrindo a possibilidade para o idoso enfrentar essa realidade, no seu tempo e com as limitações em razão da saúde físico-orgânica, mas provando a supremacia da saúde mental.

Este artigo está distribuído em três capítulos, que aborda os três eixos, ensino, extensão e pesquisa. Primeiro, repensa o currículo do curso de Direito, quando se pretende que a pessoa idosa deixe o papel de coadjunvante como disciplina optativa e passe a integrar o currículo obrigatório como disciplina eletiva. Num segundo momento, propõe-se o diálogo entre a UATI e os cursos de graduação como uma via de mão dupla. Num terceiro momento, discutir sobre a escassez dos grupos de pesquisa em Direito sobre o sujeito "Pessoa Idosa".

Além de instigadora e provocadora, a proposta constitui um dos resultados do grupo de pesquisa sobre "Direitos Humanos, Envelhecimento e Violências", inscrito no CNPq. 
Constitui uma preocupação internacional capitaneada pela Organização das Nações Unidas a Educação, a Ciência e a Cultura, discutida na Conferência Geral da Organização das Nações Unidas em 1976, realizada em Nairobi, na sua 19. a sessão (ROCHA, 2018).

A expressão «educação de adultos» designa o conjunto de processos organizados de educação, qualquer que seja o seu conteúdo, o nível e o método, quer sejam formais ou não formais, quer prolonguem ou substituam a educação inicial dispensada nos estabelecimentos escolares e universitários e sob a forma de aprendizagem profissional, graças aos quais pessoas consideradas como adultas pela sociedade de que fazem parte desenvolvem as suas aptidões, enriquecem os seus conhecimentos, melhoram as suas qualificações técnicas ou profissionais ou lhe dão uma nova orientação, e fazem evoluir as suas atitudes ou o seu comportamento na dupla perspectiva de um desenvolvimento socioeconômico e cultural equilibrado e independente (UNESCO, 1976, p. 2).

A 4a . Conferência Internacional de Educação de Adultos realizada em Paris, em 1985, manteve o tratamento dispensado nas conferências anteriores e deu um tratamento específico às Pessoas Idosas dentro da rubrica intitulada "Necessidades particulares de certos grupos: mulheres, jovens, idosos, minorias, trabalhadores imigrantes, grupos desfavorecidos, populações ameaçadas pela fome" (ROCHA, 2018).

Recomenda aos Estados membros e às organizações governamentais que facilitem o acesso dos adultos - qualquer que seja a sua idade - à educação e à cultura, a fim de que cada um possa salvaguardar o seu estatuto de cidadão a corpo inteiro e desempenhar um papel activo durante a vida e que consagrem, para o efeito, os fundos necessários, reconhecendo a educação dos adultos idosos como um investimento necessário ao equilíbrio das sociedades" (UNESCO, 1986, p. 29). (grifo meu)

O que já constitui uma realidade dos países desenvolvidos, mais antigos e com números superiores de idosos na constituição social há muito tempo, na $5^{\text {a }}$. Conferência Internacional sobre Educação de Adultos, realizada em Hamburgo, em 1997, intitulada "Aprender em Idade Adulta: uma Chave para o Séc. XXI", traz expressamente esse olhar para a população mais velha (ROCHA, 2018).

Há, actualmente, mais pessoas idosas no mundo em relação ao total da população do que nunca antes, e a proporção continua a aumentar. Estes adultos idosos podem contribuir muito para o desenvolvimento da sociedade. Logo, é importante que tenham oportuni- 
dade de aprender em igualdade de condições e de maneira apropriada. As suas capacidades e competências devem ser reconhecidas, valorizadas e aproveitadas (UNESCO, 1998, pp. 22-23).

Para marcar o acesso da pessoa idosa à educação, a fim de facilitar a sua participação ativamente na vida social, na Conferência foi escolhido o ano de 1999 como sendo o Ano Internacional das Pessoas Idosas.

\begin{abstract}
a) garantindo o acesso das pessoas mais velhas a todos os serviços e disposições que apoiam a educação e formação de adultos, facilitando deste modo a sua participação activa na sociedade; b) usando o Ano Internacional das Pessoas Idosas, e, 1999, para planear actividades que ilustrem de que forma a educação de adultos pode reforçar o papel das pessoas mais velhas na edificação das nossas sociedades (UNESCO, 1998, pp. 52-53).
\end{abstract}

Essa preocupação internacional influenciou a política brasileira para voltar os olhos para a pessoa idosa, em 1988, na Constituição da República, através dos arts. 229 e 230, e, mais significativamente com a Lei n. 8.742 de 1994, com a Política Nacional para a Pessoa Idosa, que criou as disciplinas de Gerontologia e Geriatria nos cursos de saúde, e, mais adiante, em 2003, com a instituição do Estatuto do Idoso, Lei. 10.741/2003, que reafirmou a educação como um direito social das pessoas idosas e cabe ao Estado e à Sociedade viabilizarem a sua efetividade.

Em 2000, o Ministério da Educação através da Secretaria de Educação Superior constituiu uma Comissão de Especialistas de Ensino de Direito - CEED e instituiu a Comissão de Consultores ad hoc para traçar as Diretrizes Curriculares do Curso de Direito no Brasil, atualizando as já existentes conforme a Lei de Diretrizes e Bases da Educação Nacional, Lei n. 9.394, de 20 de dezembro de 1996, a partir das indicações fornecidas pelo Parecer n ${ }^{\circ}$ 776/97 da Câmara de Educação Superior (CES), do Conselho Nacional de Educação (CNE) e pelo Edital no 4/97 da SESu/MEC, com base na Portaria ${ }^{\circ} 1.886$, de 30 de dezembro de 1994. Assim, desde a década de 90 do século XX, que se experimentou essa grade curricular com base nas novas diretrizes curriculares.

Esses parâmetros traçados constituem linhas gerais que vão orientar o projeto pedagógico de cada Instituição de Ensino Superior, "segundo suas vocações, demandas sociais e mercado de trabalho, objetivando a formação de recursos humanos com elevado preparo intelectual e aptos para o exercício técnico e profissional do Direito" (BRASIL, 2000, p.2). Esse documento critica a educação jurídica informativa e propõe flexibilização do currículo para elevar a qualidade do ensino. 
Esse "novo" sistema permite ser avaliado através da aferição das Condições de Oferta dos cursos jurídicos e a aplicação do Exame Nacional de Cursos, além da própria adoção do Exame de Ordem pela Ordem dos Advogados do Brasil, através de sua comissão de ensino jurídico.

Qual seria o perfil desejado de um formando em bacharel em Direito? Uma formação humanística, através das propedêuticas nos primeiros semestres, quiçá somente no primeiro, quando o iniciante questiona a sua utilidade? Se o discente for uma pessoa idosa, certamente terá outro perfil, com maturidade e experiência para participar e ampliar as discussões acadêmicas que não devem perder a criticidade nas interpretações, além de que não será um mero ouvinte ou principiante que, pela primeira vez ouve falar em Adorno ou Hokheimer, que questionam o certo, o justo e a retidão. Estará mais próximo de um perfil habermasiano de uma ação comunicativa e dialógica entre emissor e plateia. Seria portanto, necessário repensar o perfil de um formando em Direito para adequar o currículo à nova realidade brasileira. Não deixa de ser uma qualificação para uma nova carreira, mas não obrigatoriamente, porque a pessoa idosa pode estar cursando Direito por diletantismo, menos preocupada com as notas e mais com o espaço de socialização e oportunidade de trocas de experiências, pensando a partir das características traças no plano ${ }^{2}$.

Das carreiras jurídicas que lhe são oferecidas, apenas os concursos públicos ficarão inviáveis pela limitação constitucional da idade para aposentadoria do art. 40, aos 70 (setenta) anos, que já deveria ser repensada e modificada face ao aumento da longevidade brasileira, pari passu às regras cruéis da aposentadoria que não acompanha o reajuste ou a reposição salarial da ativa. Ficando a pessoa idosa limitada à advocacia ilimitadamente, e ao magistério privado, onde também se concentra o maior número de pessoas idosas no mercado de trabalho, porque não impõe limites temporais apenas circunstanciais em razão da idade.

Quanto às habilidades a serem desenvolvidas com o curso de Direito, a pessoa idosa irá agregar conhecimento específico ao geral que já

\footnotetext{
2 (a) permanente formação humanística, técnico-jurídica e prática, indispensável à adequada compreensão interdisciplinar do fenômeno jurídico e das transformações sociais; (b) conduta ética associada à responsabilidade social e profissional; (c) capacidade de apreensão, transmissão crítica e produção criativa do Direito a partir da constante pesquisa e investigação; (d) capacidade para equacionar problemas e buscar soluções harmônicas com as demandas individuais e sociais; (e) capacidade de desenvolver formas judiciais e extrajudiciais de prevenção e solução de conflitos individuais e coletivos; (f) capacidade de atuação individual, associada e coletiva no processo comunicativo próprio ao seu exercício profissional; (g) domínio da gênese, dos fundamentos, da evolução e do conteúdo do ordenamento jurídico vigente; e (h) consciência dos problemas de seu tempo e de seu espaço.
} 
tem domínio, e contará com a experiência da fluência verbal e da liberdade de expressão para superar barreiras tecnológicas que irá enfrentar e, com resiliência, superar. Na realidade, uma aproximação com um curso formal numa universidade é um desafio próprio, que está livre de compromisso com os outros, pois a única responsabilidade é consigo.

O projeto pedagógico dos cursos jurídicos precisa ser atualizado e inserir a pessoa idosa também no contexto da sua geografia, tanto social quanto institucional. A pessoa idosa está discente, com perfil sociodemográfico que desafia seu planejamento no sentido de revisitar lugares, pessoas, informações, para além da doutrina, da jurisprudência e da legislação, encontra-se o campo empírico latente para sair da invisibilidade e alcançar patamares cada vez mais significativos e sólidos.

A provocação se estende também à carga horária das disciplinas, da metodologia de ensino e das formas de avaliação. Pensar na aplicação de uma sala de aula invertida, por exemplo, pode ser uma oportunidade de inverter a metodologia de ensino de informação para ensino de formação, onde o discente se compromete com a pesquisa, reflexão e crítica. Conteúdos, carga horária, metodologias e avaliações precisam ser repensadas, bem como a pesquisa, a extensão e a prática jurídica.

Qual a finalidade de um curso acadêmico? Instrumentalizar o discente para a advocacia e para as carreiras jurídicas? Ou formar um cidadão consciente de seus deveres e direitos, crítico, reflexivo e potencialmente um agente na defesa do justo e do certo? Ou outras finalidades que alcancem objetivos específicos que não a coletividade, mas sim o próprio ser? Quem é esse discente que ingressou na Universidade? O que a Universidade tem para lhe oferecer? Quem sairá da Universidade depois de um curso de bacharelado em Direito? Pensar na Universidade está para além dessas perguntas, e sim qual a contribuição que a Universidade dá para as gerações presentes e futuras? Transcende os espaços físicos e repletos de discentes, e atinge o âmago do ser enquanto pessoa, sujeito de deveres e direitos. Se ele já sai com a consciência do respeito ao outro, a Universidade já terá cumprido o seu papel de instrumento para um mundo melhor, transformando em pessoas melhores para um tempo em que o respeito à dignidade da pessoa humana será natural.

Repensar também num modelo de aula, na dinâmica em sala de aula, onde os muros de uma universidade são física e psicologicamente parecidos com os muros de uma prisão, que aprisiona mentes brilhantes, de inteligências diversas, de avaliação, provas objetivas e subjetivas que 
acompanham o modelo do Exame da $\mathrm{OAB}$ e dos concursos públicos, se muitas vezes a pessoa idosa não terá oportunidade de fazer o concurso pela limitação da idade, mas a OAB que copia esse modelo de avaliação com base na informação repetitiva da memória?

Repensar que o trabalho de conclusão de curso está para além dos compromissos impostos e abissais, que será mais um resultado de várias pesquisas, questionamentos, reflexões críticas e com um contributo em potencial para repensar para além do Direito. Pensar de forma inter e multidisciplinar, porque a Ciência Jurídica não é absoluta, nem única, e não está com as suas verdades. Proporcionar o diálogo entre as ciências, ir em busca das falas da sociedade, dar voz aos invisíveis, ser protagonista dessa história e não mais um pano de fundo que entra ou ultrapassa os muros da Universidade em virtude da monarquia familiar, não dando opção à pessoa de seguir o seu próprio caminho, ainda que não saiba para onde os "ventos sopram".

Voltando a repensar o currículo na perspectiva dos eixos, o EIXO DE FORMAÇÃO FUNDAMENTAL onde estão elencadas a Ciência Política (com Teoria do Estado); a Economia; a Filosofia (geral e jurídica; ética geral e profissional); a Introdução ao Direito; e a Sociologia (geral e jurídica), em apenas um semestre contemplar conteúdos de interesses recíprocos, condensando 4 ou 5 anos de cada ciência, é uma "mágica" inexplicável, que devem fazer parte de cada disciplina do eixo de formação profissional, bem como a Psicologia, a História, a Metodologia e as Ciências da Saúde. A abertura desse eixo precisa ser pensada, discutida por cada IES, atendendo às realidades e adequando às necessidades. Crer num projeto pedagógico em constante construção e mudança para acompanhar a velocidade da evolução tecnológica, mais também da lenta transformação humana em civilizada.

O tecnicismo a e a dogmática "bobbiana" estão contemplados no EIXO DE FORMAÇÃO PROFISSIONAL, que precisa estabelecer uma inter-relação entre esses conteúdos para compreender o sistema jurídico. Direito Administrativo; Direito Civil; Direito Comercial; Direito Constitucional; Direito Internacional; Direito Penal; Direito Processual; Direito do Trabalho e Direito Tributário. E o Direito Econômico Internacional? Direito Empresarial Internacional? Direitos Humanos? Direito Humanitário? Direito dos Refugiados? Questões que transcendem o Estado brasileiro, a família brasileira, a empresa brasileira e as questões complexas sociais brasileiras. O sistema jurídico brasileiro não precisa apenas importar modelos de constituições mexicana e alemã, de controle americano ou alemão, de 
processo italiano e de direitos e garantias fundamentais franceses, é premente e urgente sua inserção no cenário internacional de forma atuante, como agente, protagonista como potência emergente, como queira, mas precisa sair da inércia e do seu "pequeno e fechado" mundo jurídico para se relacionar jurídica e politicamente com outros países.

Por fim, o EIXO DAS PRÁTICAS uma Integração entre teoria e prática das atividades didáticas e desenvolvimento das atividades do estágio de prática jurídica. Saindo do faz de conta de "Alice no país das maravilhas" e efetivamente atendendo à sociedade, com o pleno funcionamento do Núcleo de Prática Jurídica que oportunize o discente a sintetizar o conhecimento apreendido, reflexivo e crítico e a se sensibilizar com as demandas humanas e as necessidades sociais. Que efetivamente seja responsável, junto com a Universidade, pela mediação e/ou conciliação entre as pessoas que estão em litígio. E não um mero reprodutor de peças processuais num sistema de "copiar e colar" as partes, a causa de pedir e os pedidos, que são elementares em qualquer ação.

Para aprender a pessoa precisa ter um estímulo cerebral que lhe cause emoção, algum tipo de sentimento que desperte a curiosidade, a vontade de ajudar o outro, de intermediar o conflito, de desenvolver habilidades comportamentais que possam demonstrar na prática o que conseguiu apreender da teoria e testar se a proposta teórica ainda é validade no contexto social da contemporaneidade.

A Universidade também é um local democrático, que horizontaliza as suas ações, permitindo e ampliando os círculos de relações sociais. Assim são os projetos de extensão, voltados para a própria comunidade acadêmica, com os cursos de língua estrangeira, gestão e empreendedorismo, bem como para fora, para outros públicos que não estão matriculados na academia, mas que almejam conteúdos menos densos e informativos como os cursos formais. Assim são os projetos de extensão.

\section{PROJETO DE EXTENSÃO: APROXIMANDO A UATI E O CURSO DE BACHARELADO EM DIREITO}

A Universidade Aberta à Terceira Idade está prevista como uma política pública e social na Lei n. 10.741/03, mas já existia bem antes da previsão legal. 
Esse modelo de Universidade teve início através das experiências de Dumazedier com a Universidade do Tempo Livre, depois com Pierre Vellas, a Universidade da Terceira Idade de Toulouse. O que em 1973 foi pensado como um pequeno projeto, pouco tempo depois foi se agigantando e se transformou num programa regular com cursos que duravam o ano inteiro, além da criação de "unidades-satélites" da Universidade em estações de verão (terapêuticas termais) e de inverno (esqui na neve). Havia a participação ativa dos aposentados, de diferentes segmentos, que, com o tempo livre, procuravam outras experiências sem muito compromisso, responsabilidade com o ganho para a sobrevivência. (ROCHA, 2018).

Esse modelo francês foi inspirado num sistema universitário tradicional, outras nomenclaturas foram atribuídas à formação de novas Universidades, a exemplo, da Universidade para o lazer, Universidade para o Tempo Livre e Universidade Inter-idades, que ofereciam desde o acesso aberto e disponível a diferentes cursos universitários, grupos de estudo, oficinas de trabalhos, excursões e programas de saúde e de conteúdos, a exemplo da área de humanas e artes (CACHIONI, 2003). Mesmo pensando Universidade, ela abre possibilidades para o exercício com o corpo, com os sentidos, com a participação ativa e efetiva desses discentes-participantes ou participantes-protagonistas, cujo sistema de avaliação não é tão rígido e quantitativo, e sim mais aberto e qualitativo, a participação já está valendo como nota.

Quase dez anos depois, nasce em Cambridge, em 1981, o modelo inglês, oportunizando aos frequentadores do programa a atuarem tanto como docentes quanto discentes, além do engajamento com pesquisa, aproveitando a experiência e o conhecimento que as pessoas idosas já têm. Esse modelo de Universidade apresentava baixo custo e o acesso facilitado porque as atividades eram oferecidas em prefeituras, bibliotecas, centros comunitários, escolas, domicílios, além da flexibilidade de horários, currículos e métodos (CACHIONI, 2003). Na contemporaneidade, o mundo se divide entre esses dois modelos de Universidade da Terceira Idade, experiências bem novas a considerar a época contemporânea a partir da Segunda Guerra Mundial. É uma preocupação cada vez mais crescente entre os países desenvolvidos e em desenvolvimento.

No Brasil, esse modelo de Universidade chega através do trabalho realizado pelo SESC - Serviço Social do Comércio - em São Paulo, sob a influência francesa na década de 60, ao fundar os primeiros grupos de Convivência e na década de 700, as primeiras Escolas Abertas para a 
Terceira Idade, que trabalhava com temáticas sobre envelhecimento, programas de preparação para aposentadoria, atualização cultural, atividades físicas, de expressão e lazer (CACHIONI, 2003).

Coadunando com a pesquisa realizada e divulgada pelo IBGE em relação à população idosa no Brasil, que uma das maiores concentrações está nas regiões Sul e Sudeste do Brasil, a primeira experiência depois do SESC, foi a Universidade Federal de Santa Catarina que em 1982 que seguiu o modelo francês e ofereceu vagas na Universidade Aberta à Terceira Idade, uma educação permanente, não continuada, como uma proposta de curso de extensão, através do NETI (Núcleo de Estudos da Terceira Idade). Depois disso, outras Universidades no país foram criando como projeto de extensão as Universidades Abertas à Terceira Idade.

Foi na década de 90 do século XX que várias Universidades brasileiras resolveram adotar como programa de extensão e "abrir as portas" para a comunidade, através das pessoas idosas. Assim a Universidade de São Paulo

inicia a UATI em 1994, com uma proposta de integração com os jovens alunos da graduação, além de oferecer cursos gratuitos às pessoas acima de 60(sessenta) anos, além de atividades culturais e desportivas. Em 2017, a USP ofertou 4.691 vagas divididas em disciplinas regulares, oferecidas nos cursos de graduação e atividades complementares, que englobam cursos, palestras, excursões, práticas esportivas e didático-culturais. Essas disciplinas atendem à demanda das pessoas idosas, como Gestão Empresarial, Educação Ambiental, História da Música, Robótica e até mesmo Aplicação de ROVS para Mineração de Petróleo, que consiste em operar remotamente veículos no processo de mineração, estão entre os $\underline{569}$ cursos disponíveis, que são ministrados nos campi da Cidade Universitária em São Paulo, Bauru, Piracicaba, Pirassununga, Ribeirão Preto, Santos e São Carlos. As atividades esportivas exclusivas para idosos também têm vagas em programas como musculação, ginástica adaptada, pilates e dança circular. As atividades culturais são desenvolvidas com especialistas de diversas áreas, como Noções Gerais de Direito, Informática, Inglês e Criação de Textos. O programa é uma iniciativa da Pró-Reitoria de Cultura e Extensão Universitária (PRCEU) e realizado pelo Núcleo de Direitos da USP (ROCHA, 2018, p.19-20).

Essa integração ainda é muito tímida no Brasil e incipiente pensando nas regiões e num público crescente e numa demanda cada vez mais urgente. A pessoa idosa permanecendo na Universidade, através de cursos regulares ou através de projetos de extensão, evita estar nas filas do SUS, das clínicas, hospitais, buscando psicólogos, psiquiatras porque a única 
verdade que enfrenta é a morte. Idoso na Universidade é ter saúde, é sinônimo de vitalidade, de redução de demandas judiciais com os planos de saúde e com os governos, da melhoria da qualidade de vida e da garantia de seus direitos fundamentais, principalmente de sua dignidade.

Além do Texto Constitucional que traz linhas gerais sobre o direito à educação como um direito social, o Estatuto da Pessoa Idosa prevê o direito à educação no capítulo $\mathrm{V}$ nos artigos 20 a 25, os quais incluem também a cultura, o lazer e o esporte.

O artigo 21 diz que "o Poder Público criará oportunidades de acesso à educação, com adequação de currículos, metodologias e materiais didáticos destinados aos idosos", todavia o que se observa são programas de alfabetização para jovens e adultos (EJA) e não especificamente para a população idosa, com interesses bem distintos dos adultos que normalmente procuram na educação uma melhoria de sua condição socioeconômica.

O artigo 22 verifica a necessidade da inserção de conteúdos voltados ao processo de envelhecimento nos currículos mínimos dos diversos níveis de ensino formal, contudo é necessária cautela quanto à forma que esses conteúdos serão repassados, pois dependendo do teor ao apresentar o tema velhice, o mesmo pode apresentar uma ideia preconceituosa, arcaica, irrealista onde o idoso é concebido como ônus à sociedade e um problema a ser enfrentado.

O artigo 25 diz que "o Poder Público apoiará a criação de Universidades Abertas à Terceira Idade, bem como incentivará a publicação de livros com conteúdo e padrão editorial adequado ao idoso". Esse apoio ficou a cargo das Universidades Federais, Estaduais e particulares. A princípio as Universidades criaram como projeto de extensão "Universidades abertas à terceira idade", sem exigência de algum tipo de concurso ou seleção, apenas condicionando às vagas existentes; a USP é um diferencial, porque permite no curso regular a inserção da pessoa idosa, tratando-a com dignidade e capaz de construção intelectual. Talvez se pensasse numa cota "silver", uma espécie de vagas reservadas às pessoas idosas nos cursos regulares. Alguns grupos privados oferecem oficinas, cursos, palestras e viagens como uma forma de proporcionar à pessoa idosa uma melhor qualidade de vida, a exemplo da UAMA (Universidade da Maturidade Ativa) mantida pela Universidade Estadual de João Pessoa.

Constatou-se nessa pesquisa que não regras para publicação de livros com conteúdos e padrão editorial adequado ao idoso, porque não se 
discutiu qual seria esse conteúdo, nem do padrão editorial, até porque existem patologias que um jovem ou adulto têm e um idoso não apresenta, mas também patologias que vão sendo desenvolvidas no decorrer da idade avançada. Logo, não seria porque é uma pessoa idosa que exigiria algo diferente ou alterado, mas em detrimento da necessidade da patologia, independente da idade.

A Universidade Aberta à Terceira Idade (UATI) vinculada à Universidade do Estado da Bahia é oferecida como projeto de extensão nos departamentos em todo o Estado da Bahia. É uma experiência bem-sucedida, em que as pessoas idosas, independentemente do nível de instrução, socioeconômico ou de gênero, participam das oficinas que contemplam tanto a parte intelectual quanto a física, psíquica, espiritual e emocional, com aulas de informática, dança de salão, oficina de memória, cursos de línguas, dentre outros ofertados. No Departamento de Ciências Humanas e Tecnologias é desenvolvido um projeto de extensão pelo curso de Direito intitulado "Oficina de Direitos dos Idosos", com seminários, palestras, cursos, e as demandas judiciais são encaminhadas ao Núcleo de Prática Jurídica, onde os discentes do curso de Direito prestam informações e consultoria. Dessa forma, cumpre-se o que está previsto em diversas legislações, promovem-se os direitos e garante-se a dignidade da pessoa idosa. Os discentes do bacharelado têm a oportunidade de integrar e inter-relacionar com as pessoas idosas que estão matriculadas na UATI, fortalecendo o vínculo intergeracional de respeito e humanidade recíprocos.

Antes do Estatuto do Idoso, a experiência em educação se baseava na Lei n. 8.842 de 1994 (PNI), uma espécie de parâmetro legislativo para o que já havia, para o que não existia e para o que não se vê perspectiva de existência.

III - na área de educação:

a) adequar currículos, metodologias e material didático aos programas educacionais destinados ao idoso;

b) inserir nos currículos mínimos, nos diversos níveis do ensino formal, conteúdos voltados para o processo de envelhecimento, de forma a eliminar preconceitos e a produzir conhecimentos sobre o assunto;

c) incluir a Gerontologia e a Geriatria como disciplinas curriculares nos cursos superiores; 
d) desenvolver programas educativos, especialmente nos meios de comunicação, a fim de informar a população sobre o processo de envelhecimento;

e) desenvolver programas que adotem modalidades de ensino à distância, adequados às condições do idoso;

f) apoiar a criação de universidade aberta para a terceira idade, como meio de universalizar o acesso às diferentes formas do saber (BRASIL, 1994)

Certamente houve avanços, mas também objetivos que não foram cumpridos. A exemplo do ensino à distância, onde a inserção da pessoa idosa ainda é pequena, devido ao conhecimento novo que é a tecnologia atrelada à aula que deixa de ser presencial e passar a ser através do computador, uma mudança de hábito que requer tempo para adaptação. Isso pensando num idoso que tem recurso financeiro para arcar com essa despesa, contudo o idoso que sobrevive com um salário mínimo como aposentadoria, pensão ou Benefício de Prestação continuada, não há possibilidade de inserção se for acessar em sua moradia, mas pode fazer através da aula de informática na UATI.

O projeto de extensão tem um objetivo que na sua essência é recíproco, os idosos proporcionam ao discente em Direito a oportunidade da convivência, da experiência e de treinar os conhecimentos apreendidos durante o curso, além de detectar a necessidade de adquirir outros, além de ser, em potencial, uma fonte de futuros clientes em demandas judiciais, portanto, promove a experiência de como lidar com os conflitos. Para as pessoas idosas, uma oportunidade de ser ouvida, atendida, além de obter informações que antes eram difíceis de conseguir. Essa troca recíproca de conflito com solução é importante e salutar para os dois lados, por isso é importante o envolvimento do curso jurídico nas demandas sociais.

\section{GRUPO DE PESQUISA DIREITOS HUMANOS, ENVELHECIMENTO E VIOLÊNCIAS: RELATO DE EXPERIÊNCIA}

Ensino, extensão e pesquisa são importantes para apreensão do conhecimento e sua práxis. Foi utilizada a base de dados de Diretório de 
Pesquisa do CNPq com os descritores envelhecimento, pessoa idosa, idosos, velhice e terceira idade. Destes 20 (vinte) estão vinculados ao curso de Direito.

\begin{tabular}{|c|c|c|c|}
\hline Descritor & $\begin{array}{l}\text { Quanti- } \\
\text { dade de } \\
\text { grupos }\end{array}$ & $\begin{array}{l}\text { Título dos } \\
\text { grupos }\end{array}$ & IES \\
\hline Envelhecimento & 643 & & \\
\hline $\begin{array}{l}\text { Pessoa idosa nas } \\
\text { ciências sociais } \\
\text { aplicadas }\end{array}$ & 6 grupos & $\begin{array}{l}1 \text { (Direito) } \\
3 \text { (Serviço So- } \\
\text { cial) } \\
1 \text { (Turismo) } \\
1 \text { (Comunica- } \\
\text { ção) }\end{array}$ & $\begin{array}{l}\text { UNEB } \\
\text { UFES, UFPI(2) } \\
\text { UNIVALI } \\
\text { UNESP }\end{array}$ \\
\hline $\begin{array}{l}\text { Idoso nas ciên- } \\
\text { cias sociais apli- } \\
\text { cadas }\end{array}$ & 37 grupos & $\begin{array}{l}10 \text { (Direito) } \\
\text { Ciência da In- } \\
\text { formação(1) } \\
\text { Demografia(1) } \\
\text { Desenho in- } \\
\text { dustrial(2) } \\
\text { Planejamento } \\
\text { urbano e regio- } \\
\text { nal(1) } \\
\text { Serviço Social } \\
\text { (15) } \\
\text { Economia (1) } \\
\text { Economia do- } \\
\text { méstica (1) }\end{array}$ & $\begin{array}{l}\text { UERJ,UFF,UFRN,UB } \\
\text { M, UNI- } \\
\text { FOR,UFMS,URCA, } \\
\text { UEMS,UESPI,PUC } \\
\text { Minas. } \\
\text { USP } \\
\text { UNICAMP } \\
\text { UEMG } \\
\text { UFSCAR,UTFPR } \\
\text { UFRN } \\
\text { PUC(SP),UNESP,UFF, } \\
\text { UFPE,UFR- } \\
\text { SITE,PUC(SP),UFVJ } \\
\text { M,UNI- } \\
\text { TAU,UFPI,UFF,UFPB, } \\
\text { ITE,UFPI,UFF } \\
\text { UFMG, }\end{array}$ \\
\hline
\end{tabular}




\begin{tabular}{|c|c|c|c|}
\hline & & $\begin{array}{l}\text { Comunicação } \\
\text { (2) } \\
\text { Turismo (1) } \\
\text { Arquitetura e } \\
\text { Urbanismo (1) } \\
\text { Administração } \\
\text { (1) }\end{array}$ & $\begin{array}{l}\text { UFV } \\
\text { ESPM, UNESP } \\
\text { UNINOVE } \\
\text { UFJF } \\
\text { UEPB }\end{array}$ \\
\hline $\begin{array}{l}\text { Velhice em Ciên- } \\
\text { cias Sociais Apli- } \\
\text { cadas }\end{array}$ & 12 grupos & $\begin{array}{l}\text { Comunicação } \\
\text { Serviço } \quad \text { so- } \\
\text { cial(11) }\end{array}$ & $\begin{array}{l}\text { ESPM } \\
\text { PUC(SP)(3),UFRB(2), } \\
\text { UFAM,IFCE,UNITAU } \\
\text {,UFES,UFF,UFPB }\end{array}$ \\
\hline $\begin{array}{l}\text { Envelhecimento } \\
\text { em Direito }\end{array}$ & 3 grupos & 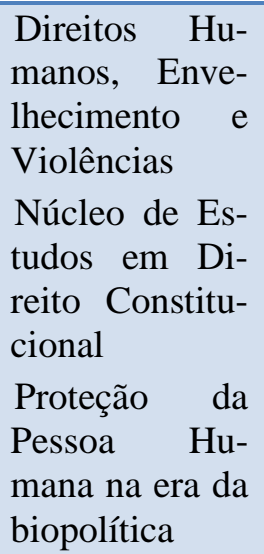 & $\begin{array}{l}\text { (UNEB) } \\
\text { (UFMA) } \\
\text { (UERJ) }\end{array}$ \\
\hline $\begin{array}{l}\text { Terceira idade } \\
\text { em Direito }\end{array}$ & 3 grupos & & $\begin{array}{l}\mathrm{PUC}(\mathrm{SP})(2) \\
\mathrm{UFF}\end{array}$ \\
\hline $\begin{array}{l}\text { Terceira Idade } \\
\text { em Ciências Soci- } \\
\text { ais Aplicadas }\end{array}$ & 12 grupos & $\begin{array}{l}\text { Direito } \\
\text { Serviço Social } \\
\text { Turismo } \\
\text { Administração } \\
\text { Desenho in- } \\
\text { dustrial } \\
\text { Arquitetura e } \\
\text { Urbanismo }\end{array}$ & $\begin{array}{l}\text { PUC(SP)(2), UFF } \\
\text { UFF, UFRB, UFPI(2) } \\
\text { UNINOVE } \\
\text { UEPB } \\
\text { IFMG, UTFPR } \\
\text { UFJF }\end{array}$ \\
\hline
\end{tabular}

Fonte: http://dgp.cnpq.br/dgp/faces/consulta/consulta parametrizada.jsf 
Para o curso de Direito no Brasil, abordar a temática do Idoso ou do Envelhecimento ainda é uma novidade, em que pese muitos profissionais da área serem pessoas idosas e existirem muitas demandas envolvendo idosos como plano de saúde, moradia, alimentos e crimes praticados contra idosos.

A proposta do Grupo de Pesquisa em Direitos Humanos, Envelhecimento e Violências é mapear todas as demandas judiciais e extrajudiciais que envolvem as pessoas idosas, acima de 60 anos, separar por matéria, identificar a(s) violência(s), discutir e analisar esses fatos sociais e publicar os resultados de pesquisa em livros e periódicos, divulgando-os em seminários, congressos e outros eventos de natureza nacional e internacional.

Um dos resultados do grupo de pesquisa foram dois artigos aceitos e apresentados no $56^{\circ}$. Congresso Internacional de Americanistas, ocorrido em julho em Salamanca na Espanha, um tratando sobre a violência contra as mulheres na cidade de Brumado e o outro sobre o acesso à justiça através do balcão de justiça da cidade de Valença, ambas na Bahia.

Este grupo de pesquisa está interligado com o ensino na graduação em Direito, com a produção científica nos trabalhos de conclusão de curso do bacharelado em Direito; com o projeto de extensão "Oficina de Direito dos Idosos", com o programa na rádio Rede Vida, 83.9 em Brumado, intitulado "Fala AMA" (Amadurecimento e Maturidade Ativa). Avanços estão planejados como uma revista eletrônica vinculada à UNEB, DEV (Direitos Humanos, Envelhecimento e Violências), com publicação semestral e indexada, e com um Seminário Nacional sobre Direitos Humanos, Envelhecimento e Violências a ocorrer anualmente na cidade de Brumado/Bahia.

As reuniões do grupo de pesquisa são semanais, previamente agendadas, com participação aberta, os discentes estão inscritos no grupo de pesquisa no $\mathrm{CNPq}$, além de outros pesquisadores a nível nacional e internacional. Há um cronograma estabelecido com leituras, discussão, produção de artigos para publicação em congressos, seminários, periódicos e livros digitais e físicos. O grupo também organiza seminários locais, reuniões com o poder público, organizando uma rede de proteção à pessoa idosa. Os agentes que atuam na Universidade, docentes, discentes, técnicos estão cumprindo o seu papel de responsabilidade social e interligando o tripé, que geralmente é dissociado. 


\section{CONSIDERAÇÕES FINAIS}

Sênior, pessoa maior, idoso, velho, terceira idade são nomenclaturas atribuídas internacionalmente às pessoas que têm mais de 60 ou 65 anos, dependendo se o país for classificado como em desenvolvimento ou desenvolvido, respectivamente.

O curso de bacharelado em Direito não tem uma disciplina obrigatória que estude os direitos das pessoas idosas e poucas são as publicações na área. No máximo, integra uma disciplina que contempla ECA e Idoso, como disciplina optativa. Demonstrando o desinteresse e a falta de conhecimento com os interesses da pessoa idosa.

Na conjuntura e contexto atuais não há como se pensar num curso disciplinar quando as temáticas são interdisciplinares, inclusive dentro do próprio curso jurídico. Pensar sobre pessoa idosa é buscar referências no Direito Civil, Penal, Previdenciário, Processual, Tributário, Empresarial, Trabalhista, Administrativo, Internacional, bem como nas propedêuticas, Psicologia, Sociologia, Filosofia, Economia, dentre outras.

Projetos de extensão também precisam ser pensados não somente como complemento na formação do bacharel em Direito, mas também no movimento inverso, com o conteúdo apreendido, o discente poder informar o quê absorveu. Ele precisa desse movimento até para mensurar até onde foi capaz de compreender, interpretar e discutir sobre a temática envolvida.

Ademais, numa formação universitária, a pesquisa é imprescindível, porque sem desenvolver o espírito de busca, como ficam a investigação na doutrina, na jurisprudência e a possibilidade criativa do ser humano? O ato de pesquisar está para além das fronteiras do eu, é a abertura que se faz ultrapassando barreiras nacionais e internacionais. É o ato incansável de trocar com os outros métodos, questões, metodologias, técnicas e resultados. E mais que isso, da consciência da pequenez humana, das verdades relativas e da flexibilidade e humildade postas a toda prova.

O Núcleo de Prática Jurídica precisa fazer intervenções sociais, precisa ser útil à sociedade, podendo amplamente atuar nas questões extrajudiciais, prestando consultoria às pessoas, independentemente de sua vulnerabilidade. Principalmente nas Universidades Públicas, que os discentes estão sendo beneficiados indiretamente com os impostos que pagam ao governo, e diretamente com os impostos que são pagos pela coletividade. Então precisam prestar serviço público daquilo que o público investiu e investe neles. 
É fato, social e crescente, há uma preocupação internacional com o envelhecimento humano, social, das cidades, da economia, dos valores, e não há uma direção para a preservação com as espécies, demonstrada através das crises, guerras, fome e miséria. Os seres humanos estão se afundando nas crises externas, mas a interna é a mais destruidora delas, com depressão, sem referências, nem valores, a pessoa volta-se para si, no seu egoísmo e materialismo, sem rumo, sem direção, sem família, sem a consciência da coletividade, das carências e necessidades do outro, da importância que o alter tem em sua vida. Pensar e valorizar a pessoa idosa constitui uma obrigação natural e não se discutir sobre a falta dessa obrigação. Está a se discutir uma questão de consciência de humanidade, onde só restará para o ser humano destruir um ao outro.

Quanto aos grupos de pesquisa sobre envelhecimento, dos 643 grupos inscritos no CNPq, apenas 20 estão vinculados ao curso de Direito em todo o Brasil, demonstra poucos pesquisadores na área de investigação, além de uma supremacia do Serviço Social na área das Ciências Sociais Aplicadas, mas uma hegemonia da área da Saúde na pesquisa sobre as pessoas idosas, justificando um olhar sensível, uma maior preocupação com a questão que é fato e está posta com a prospecção das pesquisas internacionais de que o Brasil ocupará a sexta posição de população idosa em 2050.

Destarte, há que se repensar o envelhecimento como disciplina obrigatória da grade curricular do curso de Direito, bem como a ampliação em projetos de extensão e pesquisa científica.

\section{REFERÊNCIAS BIBLIOGRÁFICAS}

ASSOCIAÇÃO BRASILEIRA DE NORMAS TÉCNICAS. NBR 6023: informação e documentação: referências: elaboração. Rio de Janeiro, 2002.

BRASIL. Constituição (1988). Constituição da República Federativa do Brasil. Brasília, DF: Senado, 1988.

. Lei ${ }^{\circ} 10.741$ de $1^{\circ}$. de outubro de 2003. Dispõe sobre o Estatuto do Idoso. Diário Oficial da União, Brasília, DF, v. 134, n. 248, 23 dez. 2009. Seção 1, p. 27834-27841.

. Lei $n^{\circ} 8.842$ de 4 de janeiro de 1994. Dispõe sobre a Política Nacional do Idoso, cria o Conselho Nacional do Idoso e dá outras providências. Diário Oficial da União, Brasília, DF, 6 janeiro 1994. 
Ministério da Educação. Diretrizes Curriculares do Curso de Direito no Brasil, 2000. Disponível em: http://portal.mec.gov.br/sesu/arquivos/pdf/dir_dire.pdf. Acesso em 1º. Ago 2018.

CANCHIONI, Meire. Envelhecimento Bem-sucedido e a Participação numa Universidade para a Terceira Idade. Dissertação de Mestrado, Faculdade de Educação, Unicamp, 1997.

Quem educa os idosos? Um estudo sobre professores de Universidades da Terceira Idade. Campinas, SP: Editora Alínea, 2003.

DUMAZEDIER, Joffre. Sociologia Empírica do Lazer. Trad. Silvia Mazza e J. Guinsburg. 3.ed. São Paulo: Perspectiva: SESC,2008.

INSTITUTO BRASILEIRO DE GEOGRAFIA E ESTATÍSTICA (IBGE). Síntese Indicadores Sociais - Uma Análise das Condições de Vida da População Brasileira. Disponível em: https://biblioteca.ibge.gov.br/visualizacao/livros/liv98887.pdf. Acesso em: $1^{\circ}$. Ago 2018.

ORGANIZAÇÃO DAS NAÇÕES UNIDAS. UNESCO, 1986. 4ª . Conferência Internacional de Educação de Adultos realizada em Paris, em 1985.

robi, na sua $19 .^{a}$ sessão.

Conferência Geral da Organização das Nações Unidas em 1976, realizada em Nai-

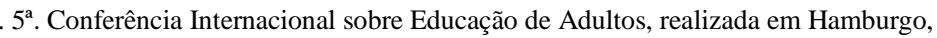
em 1997, intitulada "Aprender em Idade Adulta: uma Chave para o Séc. XXI".

ROCHA, Sheila Marta Carregosa. DIAS, Rosana de Queiroz. DIREITO E IDOSO: NOVAS TENDÊNCIAS NO ENSINO JURÍDICO. Anais do Sciencult. Paranaíba. v. 4. n. 1. p. 152-159. 2012.

ROCHA, Sheila Marta Carregosa. O DIREITO DO IDOSO À EDUCAÇÃO: MAPEAMENTO DE EXPERIÊNCIAS VOLTADAS AO ENSINO, ARTE E LAZER ATRAVÉS DAS UNIVERSIDADES ABERTAS À TERCEIRA IDADE. In:. Educando para envelhecer: Trajetórias, estudos, relatos e pesquisas. Orgs. Manoel Freire de Oliveira Neto, Rozeane Albuquerque Lima e Lindomar de Farias Belém. Paraíba:EDUEPB, 2018. 